soft. Both sixth nerves were flattened in their course at the base of the skull, especially the left, which was atrophied. The other nerves appeared healthy. There was no disease of the thoracic or abdominal organs. Presumably the left facial and auditory nerves were involved in the thickening of the dura mater, which also involved the left lateral sinus.

It is curious that there is no record of the occurrence of St 3 , which are so common and almost characteristic of the presence of gummata. It is curious, too, that until quite a late period the only paralysis present was that of the left facial nerve. In connexion with the subject of large cerebral gummata, of which the last case furnishes a noteworthy example, I will make a brief reference to another case that came under my care in 1880. The patient was a young woman who was transferred from King's College Hospital to St. Thomas's Hospital on July 14th. I received no history with her beyond the statement that she had been suffering while in King's College Hospital from unilateral epileptiform attacks. On admission she was somi-comatose. She did not speak or take notice excepting when attempts were made to move her limbs or open her eyelids. which she resented. She had no definite paralysis, but swallowed with difficulty. The right pupil was larger than the left, and neither acted to light. She had double optic neuritis. Her temperature on admission was $99 \cdot 6^{\circ}$; the next morning it was $1016^{\circ}$. Towards the afternoon of this day she sank into profound coma and her temperature rapidly rose; and just before death, which took place in the evening, it reached $107 \cdot 4^{\circ}$. On post-mortem examination depressed scars were noted on the forehead, chest and back, and there was a syphilitic gumma as large as hen's ego embedded in the rioht anterior cerebral lobe, with thickening and adhesion of the membranes over it. The vessels were healthy. The only other evidence of disease was the presence of scars on the surface of the liver and spleen.

Before I conclude wy lecture I should like to quote one ofher case, in this instance not fatal, which presumably was much of the same character as the last but one; for in its course the ears became affected, both facial nerves became paralysed, she had double optic neuritis and hemiplegia ; but additionally she had marked evidence of syphilitic involrement of the pericsteum of the skull

A married woman aged twenty-five was ndmitted under my care on March 19th, 1878. After the birth of her first child she had an eruption on the legs and her hair came off The child died when seven months old and was said to have been syphilitic. Sis months previously she had a fall from a trap, struck her head and face, and was stunned and insensible for two hours; but she recovered completely in a short time. On Jan. 1st she arroke in the morning with violent pain at the top of the head, where also it was swollen and tender, An incision was made, but only a little blood escaped. Since then the pain has been almost constant. She was healthy looking, but complained of severe pains in the forehead and sides of the head and face and in the eyes, ears and teeth, which were worse at night, and of which the pains in the eyes and ears were agravated respectively by light and noise. Her eyelids were swollen and there was puffiress and considerable tenderness over the forehead and sides of the head. She was quite sensible. There was no paralysis or anæsthesia. She had double optic neuritis. On April 27th it was remarked that the severe pain continued in the head, ears and teeth; that the headache was apt to shift, being worst sometimes in front, sometimes behind, sometimes at the sides; that there was much tenderness and cdema, especially about the zygomatic regions; that the temporal muscles acted imperfectly; that a tender swelling had appeared towards the back of the left side of the head; and that she was frequently sick. On May 26th note was made to ine effect that the pains had continued and were sometimes so severe (especially at night) as to nuake her scream, at which times also she was apt to be delirious that during the last few days the pain had been localised mainly in the mastoid regions; and that her sight was failing. About a week later it was observed that she had commencing paralysis of the left portio dura, and that she complained of diplopia. At this time it was also noted that the discs were hazy, their outlines blurred and surrounded by a grey zone; that there was some swelling; and that the ressels were tortuous and the veins enlarged. The facial paralysis increased during the neat week or two and then slowly subsided. In the beginning of July (by which time the cedema and tenderness had disappeared from the frontal, temporal and zygomatic regions and there was scarcely a trace of left facial palsy) she complained of pain and stiff ness in the back of the head and neck and of severe pain in the ears. Soon after this, the pains continuing, she became deaf on both sides; on July 18th it was observed that since the day. before she had been completely deaf and had had noises in her ears ; and on or about the 25 th she had a copions discharge from both ears and she could not quite close the right eye. From this date improvement, on the whole, continued, she soon lost all pain in or about the head, and she expressed herself as feeling quite well but for the gathering in her ears and "the beastly taste in her mouth." But the discharge from the ears continued, both membranx tympani were found to be perforated, she remained almost absolutely deaf and the paralysis of the right portio dura became almost complete. She left at her own wish on Aug. 3rd, having been in the hospital nearly five months. The patientagain came under my care six years later. She then stated that but for persistent deafness and occasional discharge from her ears she had quite recovered and had continued well until recently, when she had recurrence of severe headache. This became aggravated a fortnight before admission and was attended with return of discharge from the left ear. A week later she was seized with romiting and observed that her right arm and leg were weak. On admission she was restless and moaning with pain, which she referred to the forehead and left side of the head, suffered from vomiting, and presented complete left facial palsy with slight but obvious weakness in the right arm and leg. There were traces of the old optic neuritis. She again improved under treatment and left well but for persistent facial palsy.

In this case there was evidently abundant syphilitic affection of the periosteum of the skull and not improbably of the soft parts superficial thereto. The middle ears were also implicated; and there can be little doubt that the dura mater shared in the mischief. The variable facial palsy and the deafness may have been due to the ear affection. On the other hand, they may have resulted from implication of the nerves in disease of the dura mater, an explanation which may equally apply to the pains in the domain of the fifth pair. The optic neuritis and temporary right hemiplegia point of course to the presence of intra-cranial disease. I need scarcely say she was treated systematically on both occasions with mercury and iodide of potassium.

\section{CASE OF SYRINGOMYELIA, WITH NECROPSY.}

BY JAMES TAYLOP, M.A., M.D. EDIN, M.R.C.P. LOND., REgISTRAR AND PATHOLOGIST TO THE NATIONAL HOSPITAL FOR THE PARALYSED ATD EPILEPTIC, QUEEN-SQCARE, W.C.

I AM indebted to the kindness of Dr. Charlton Bastian for permission to publish the following case. I also have to thank Dr. Howard Tooth for rarious particulars as to the history of the patient whilst he was under his care at the Metropolitan Hospital and subsequently as an out-patient at the National Hospital for the Paralysed and Epileptic, Queen-square. The notes of the case whilst the patient was under Dr. Bastian's care were taken by Drs. Rivers, Page May "and Batten. In May of last year I showed the cord and described some of the sections at a meeting of the Neurological Society.

A tobacconist's assistant aged twenty-three, single, had had fairly good health until February, 1889, at which time he was said to have had an attack of bronchitis. While he was convalescing from this illness objects seemed unsteady when he looked at them, and he walked as if he were intoxicated. After this he had weakness and tingling in his righ arm, and had difficulty in swallowing liquids. His condition improved after a lapse of two months, but he still had some dificulty in walking, staggering at times and being very short of breath. In October of the same year he became worse. He was more unsteady in walking and would sometimes fall, but without losing consciousness. He had pains in his legs and objects seemed to dance before his eyes. He became steadily worse, but had no difficulty with the rectum or bladder. He became a patient at the Metrepolitan Hospital and Hackney Infirmary. At the former he had a full mercurial course. His health previously to the onset of this illness was fairly good. He had measles in 1882, scarlet 
fever in 1883 and small-pox in 1884. In 1886 he fractured His mother was alive and suffered from neuralgia, but his his left arm and dislocated his elbow. He was treated at the German Hospital, but the limb remained weak and was frequently painful. Although he dated his illness from 1889 it is a significant fact with reference to what will presently father was dead. 'The cause of death was not known. No history of nervous disease in any relative was elicited. The patient was an only child. When he was admitted to the hospital in January, 1891, he complained of unsteadiness in walk-

FIG. 1.

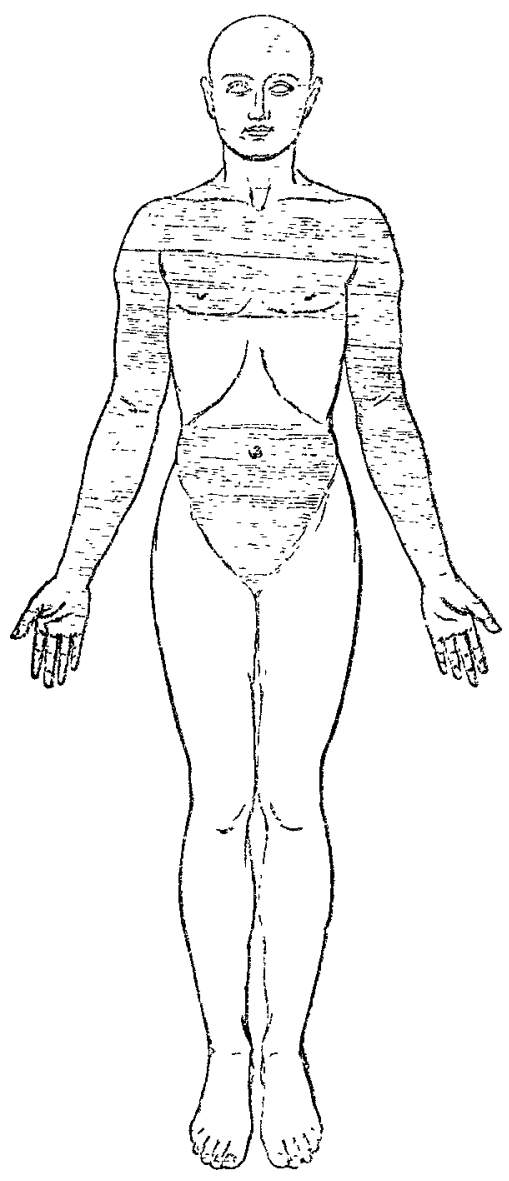

FIG. 2.

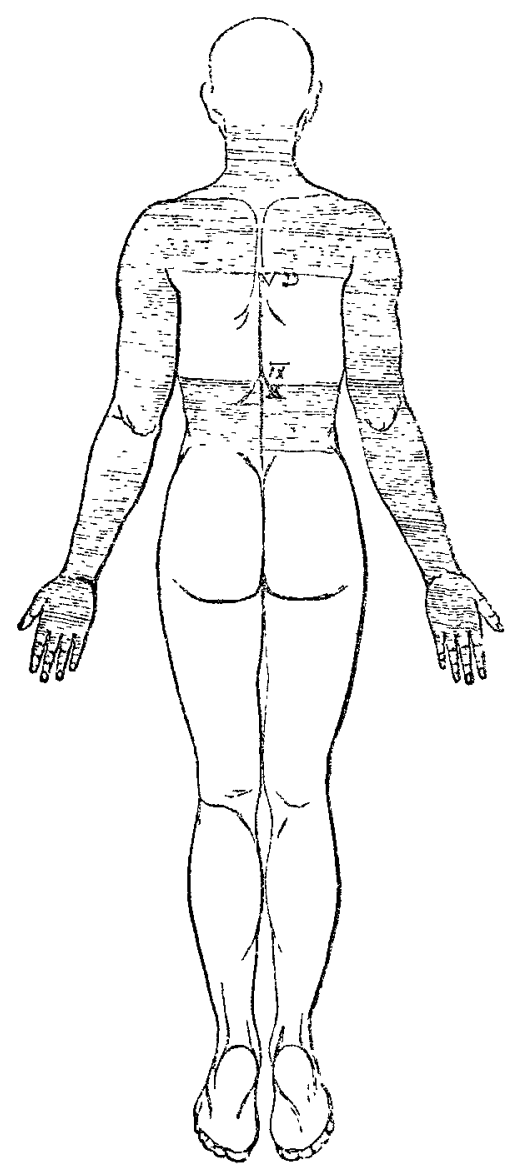

be related that in 1886 he burnt his right arm with a hot rai whilst asleep, and although the burn was so severe as to leave a scar of considerable size he suffered no pain from the accident. His family history disclosed no fact of importance.

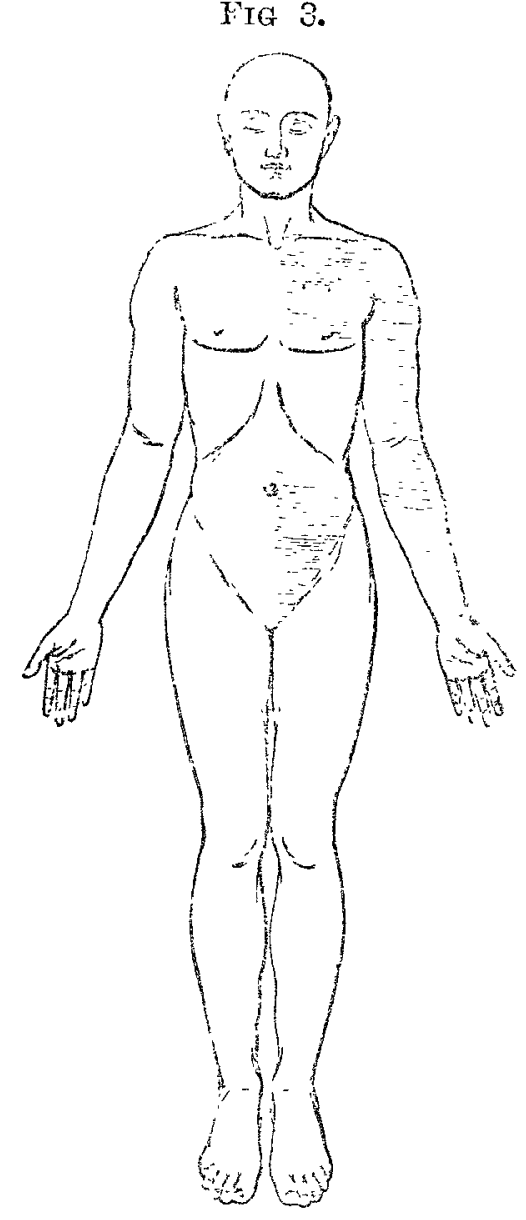

FIG. 4.

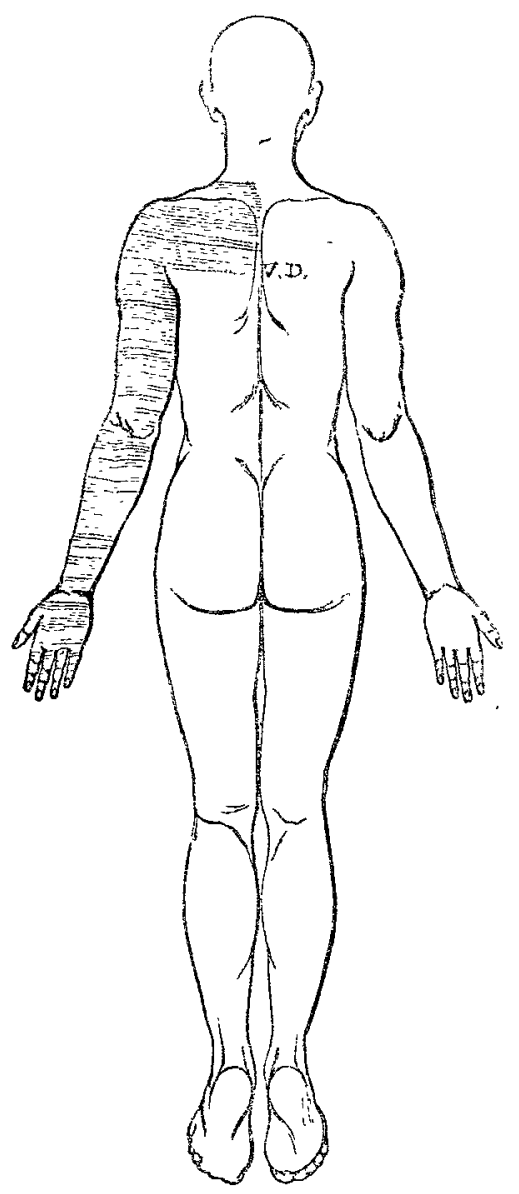

ing and numbness about the left hip. He also said that objects seemed to move before his eyes. The conditions disclosed by examination were as follows: All the movements of the head on the trunk were well performed. The ocular [movements 
were good, although vertical nystagmus was present during rest even, and became more evident and assumed a rotatory character on lateral deviation to either side. The pupils were equal and reacted normally to light and during accommodation. No change was seen in the fundus. There was no asymmetery of the face, and the palate movement and the action of the masseters were normal. There was no deviation of the lower jaw on opening the mouth. The hearing was good. As regarded the upper limbs on the right side there was some wasting of the thenar muscles and the trapezius was definitely atrophied. All the movements of the hand and farearm were well performed. The arm could be raised above the head fairly well and the shoulder could be

FIG. 5.

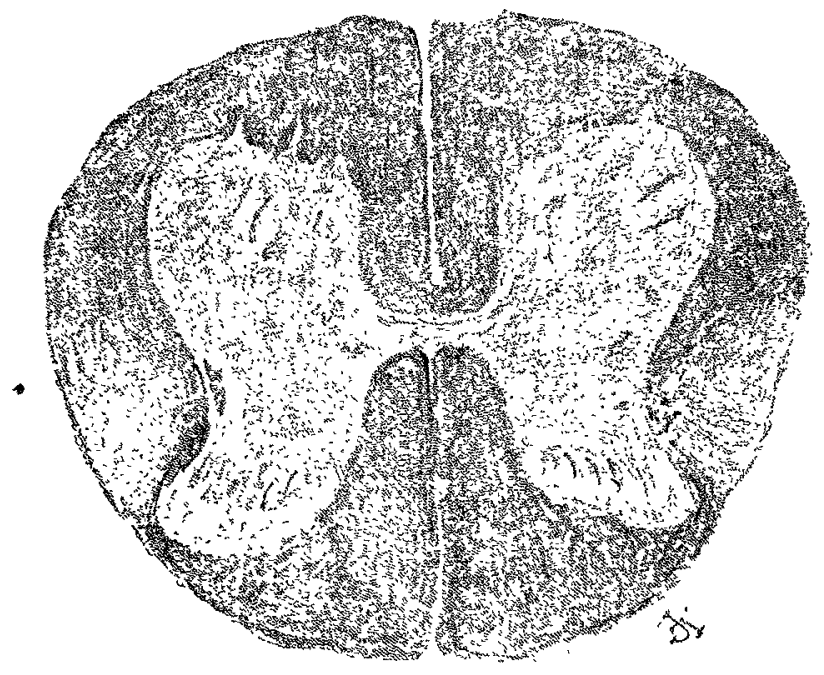

horagged, although not so well as on the opposite side. on the left side the movements and muscles about the elbow and hana were normal, although there was marked deformity of the elbow-joint and forearm, the result of the accident in 1886 already alluded to. The grasps as tested by the dynamometer were 60 with the right hand and 55 with the left. The patient was right-handed. In the lower limbs all the movements were good and there was an absence of wasting. Both knee-jerks were active; on the left side there was ankle-clonus, but this was not present on the right side. The plantar reflexes were both active, the right more so. The gait was unsteady and there was difficulty especially in turning. The patient could not stand

FIG. 6.

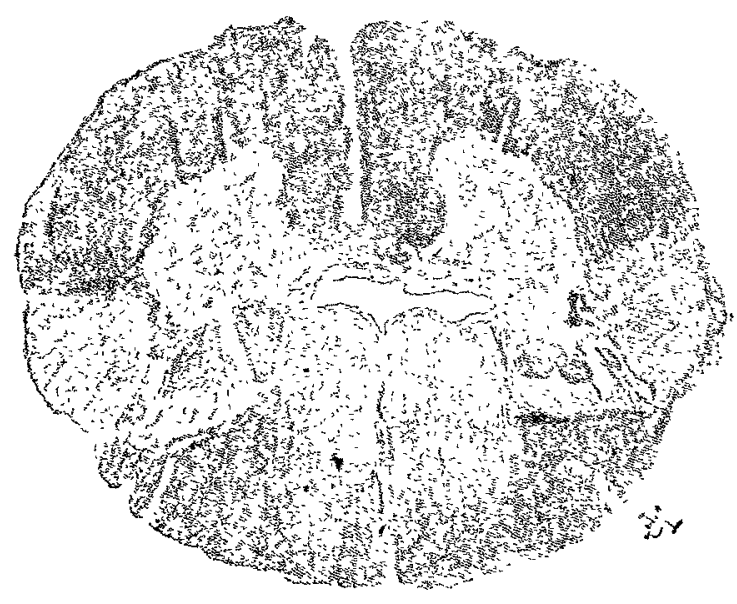

with his eyes closed. There was no dragging of the feet in walking. As regards sensation the sense of position was good everywhere except in the left upper limb, in which it was impaired at the elbow and absent in the hand and fingers, so that he was unable to tell whether the hand was flexed or extended at the wrist and whether the fingers were bent or straight. The condition of zensibility to ligbt touches and to painful and thermal stimuli as such will be better comprehended from the accompanying diagrams than from any verbal description. In Figs. 1 and 2 the shaded areas show where thermal and painful impressions as such were not perceived. In those areas, except the parts indicated by skading in Figs. 3 and 4 (in which light touches were not per- ceived), and on the rest of the body sensibility to tactile impressions was not impaired. There was undue prominence of the fifth dorsal spine and some reddening and thickening over it. The heart and lungs showed no evidence of disease. An accident of some interest happened while the patient was in hospital. He one day caught hold of a kettle with his righ hand. He did not notice that it was hot and the largo blister which resulted caused him no pain. The blister was on the inner side of the right index finger. During the time he was in hospital the patient remained fairly well and was able to be up erery day and to move about the ward. In April, however, he was attacked by bronchitis accompanied with great cardiac weakness, to which he succumbed.

Fig. 7.

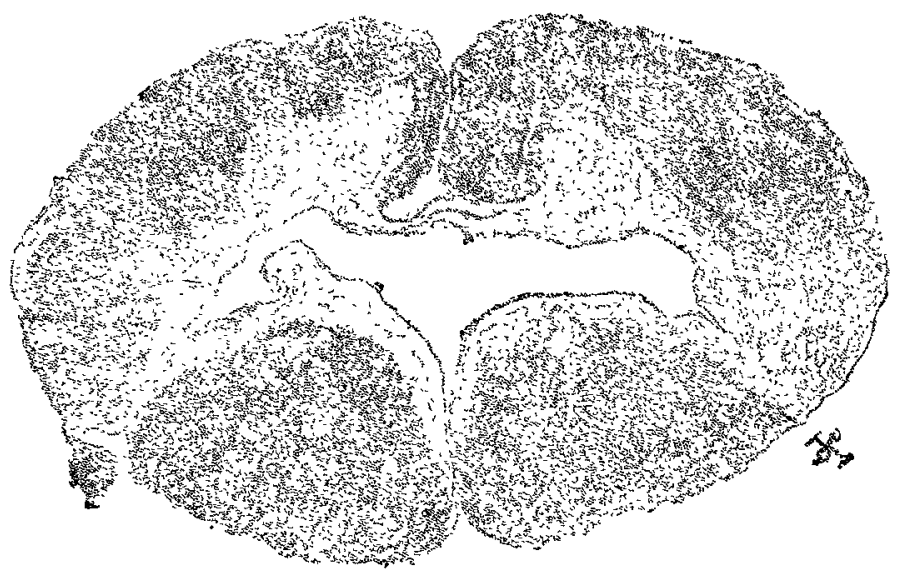

At the necropsy, which was limited to the back at the request of the friends, the bronchi and bronchioles were found to be in a state of acute inflammation. The lungs were œedematous. There was no sign of any morbid cardiac condition. In the spinal column there was no bone disease. The cord was very soft and flaccid and was greatly dilated in the centre. This was greatest in the cervical region, gradually lessening downwards, so that in the upper lumbar part of the cord it was a mere slit and in the lower lumbar no unusual appearance was visible to the naked eye. The aqueduct of Sylvius was also considerably dilated. After the cord had been hardened in Muiller's fluid sections were prepared from different levels with a view to answering the two questions which arise : (1) What was the nature of the anatomical change and its etiology? and (2) how were the symptoms which were present during life in this patient related to the anatomical conditions found after death?

Frg. 8.

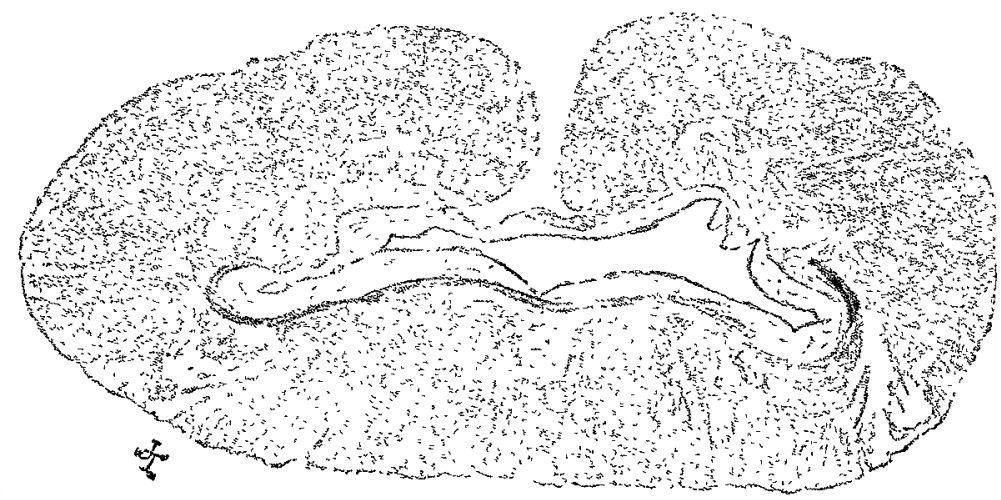

With reference to the anatomical change which was found on closer examination the accompanying figures will indicate the condition. Fig. 5 is a drawing of a section from the lower lumbar region and it can be seen that the central canal at this level is little, if at all, changed. The darkly shaded parts in these figures indicate the parts where the fibres are normal, while the lighter parts show where the fibres are deficient or absent. In Fig. 5 there is evident sclerosis in both lateral pyramidal tracts, but it cannot be said that this is more extensive in one than in the other. In Fig. 6, from a section in the upper lumbar region, the same condition is seen to be present; but there is in addition an opening of some size in the position of the central canal. This has at points, not in its entire circumference, a lining consisting of cylindrica! epithelium, pointing, I believe, to 
the fact that part at least of this cavity represents the true central canal. Besides the sclerosis in the lateral pyramidal tracts already mentioned, there is also at this level considerable change of similar character in the posterior columns, especially at their central ends. The anterior horns are normal and the cells appear unaltered. In Fig. 7 the cavity is much larger, extending into, and to a great extent destroying, the posterior horns. Around this cavity, most evident posteriorly, there is an area of tissue in which no nerve fibres can be detected, but which has the appearance of fibrous tissue. This passes down into the situation of the posterior fissure. The anterior horns, apart from the distortion which such a condition as is present must entail, seem to be normal. Fig. 8 is from a section in the lower cervical region, and in it the central cavity is still larger. It has here and there an epithelial lining of the same character as is visible in the sections already described. The posterior horns are here also seen to be encroached upon, and around the cavity there is a well-marked area of tissue identical in appearance with that described in the last section. In the posterior horn region there is also the appearance of sclerosis and at the central end of the posterior column there is a curious definitely marked area in which very few nerve fibres are present. There is also a scantiness of these in the posterior columns generally, most marked at the dorsal part. The presence of the cavity has also given rise to the circuitous route of some fibres, of which the origin and destination are not evident, and to very considerable distortion of the anterior horns. In the upper cervical region (Fig. 9) the cavity has reached its maximum. Here also, as elsewhere, there is visible at parts an epithelial lining. The absence of fibres is con- cord are : (1) That especially of Virchow, according to whick a congenital abnormality is supposed to be the determining cause of a central cavity -i.e., that a condition of syringomyelus starts as one of hydromyelus; (2) the view that a cavity or cavities in the cord are the result of central growth: (3) that which supposes that there is a chronic inflammatory process around the canal, or that there is inflammation apart from the canal and that holes are formed in the cord as a result of softening; (4) that enlargement of the canal is the result of obstruction to the blood-flow into the skull, leading to excess of fluid in the cord, which transudes into the canal and leads to its enlargement. A similar condition is sup. posed to arise from pressure on the cord itself by means of tumours, meningitis \&c.

At the time of the necropsy on the patient whose case is under consideration the central cavity of the cord was full of fluid, and the cord, especially in the cervical region, felt like an indiarubber tube full of fluid. On examination this cavity was found to have, in parts at least, a distinct epithelial lining of the kind usual in the central canal. The tissue around the cavity may be regarded either as a form of new growth or as the result of some abnormality in development. The curious way in which it is disposed is, I think, against the former view, and I regard the latter as much more probable, especially having regard to the other conditions present. The appearance of a condition in some way resembling sclerosis, especially around the posterior horns and in the posterior columns, has been referred to At one point in particular this is very marked-viz. at the central end of the postero-internal columns and in view of the explanation of the tissue round the cana

FIG. 9.

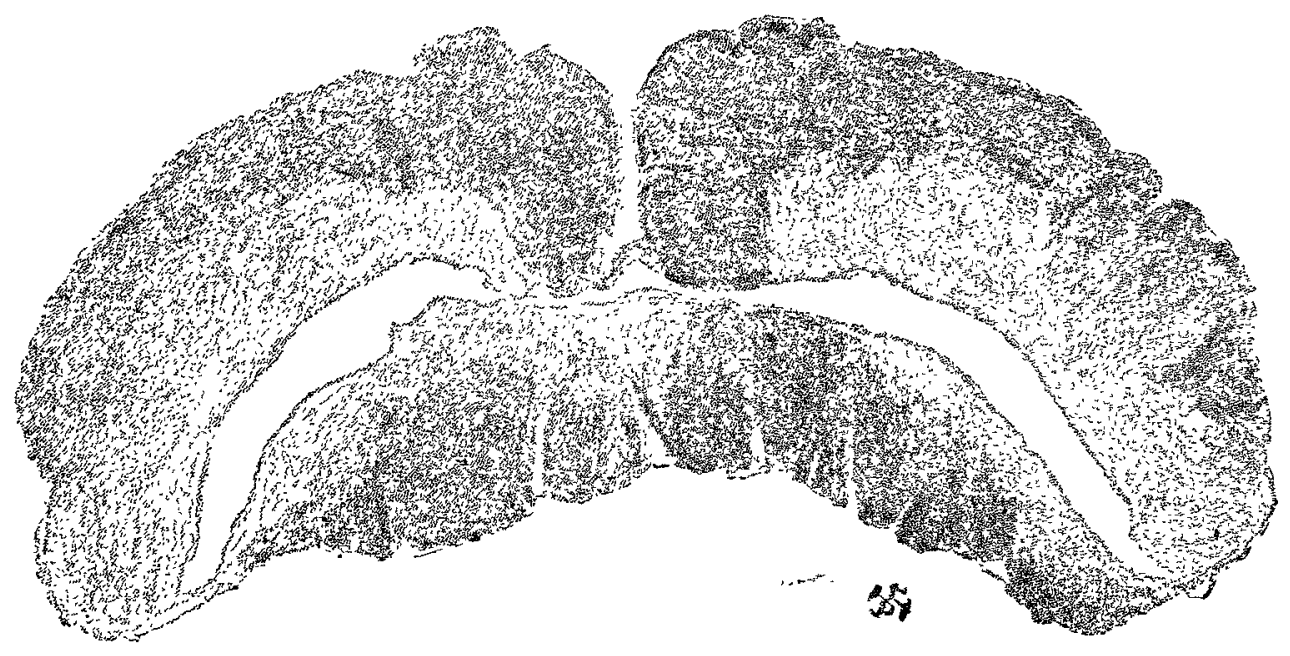

spicuous in the region of the posterior horns, which the cavity has deeply invaded and indeed destroyed. This is also evident in the posterior columns, especially centrally, in the region corresponding to that referred to in the last figure. The anterior horns are spread out as a result of the pressure of the large cavity. Cells are visible in them in some numbers, but their outline is less clear than is usual and the ordinary arrangement in groups cannot be verified. In the medulla the canal is also enlarged, although not to any great extent. After the canal has opened out into the fourth ventricle no marked change is evident except that the whole structure appears flatter, as if its horizontal diameter had increased at the expense of its antero-posterior. Some of the bundles composing the ascending root of the fifth nerve on both sides are altered, as if the gelatinous tissue had encroached upon the area occupied by the nerve fibres. When the iter is reached this is found to be considerably dilated. As permission to examine the brain was not obtained the condition of the ventricles cannot be described.

Such are the anatomical changes; before proceeding to consider their significance, it may be well to inquire into the etiology of the condition just described. In my attempt to do so I have to acknowledge my indebtedness to the last edition of Dr. Gowers' Manual and to the exhaustive monograph by Professor Hoffmann of Heidelberg, ${ }^{1}$ whilst in no way wishing to saddle these writers with any responsibility for statements from which they may possibly differ. The four views enunciated by Professor Hoffmann as to the etiology of these conditions in the

I. Deutsche Zeitschrift für Nervenheilkunde. as depending ultimately on some abnormality of development it is significant that this condition of excess of connectivetissue elements at the expense of nervous is present in the posterior columns, the last large division of the cord to be supplied in the course of development with nervous elements, and is actually most marked at the point in those columns which is the last of all to be furnished with nervous tissue proper-viz., the central end. Having regard to these facts, therefore, I am inclined to look upon the condition present in this case as one of defective development in the first place, not sufficiently important in an early stage in all probability to produce at least obtrusive symptoms. On the congenital anomaly a process of growth was later, so to speak, engrafted, so that finally there was, I believe, the original condition 'not altered in kind but merely in degree, representing rather a process of overgrowth than of new growth.

I would now briefly allude to the second question which I have proposed-viz. What is the relation of the symptoms to the anatomical changes which were present? With regares to the face, the anæsthesia was possibly determined by the slight change in the ascending root of the fifth, and the nystagmus was probably dependent upon slight functional disturbance of the nuclei of the ocular nerves resulting from the dilatation of the aqueduct of Sylvius. So far as the condition of the cord is concerned, one fact is evident-viz. that the posterior root region and the posterior columns are most affected. To the former are probably to be ascribed the sensory impairment and to the latter may have been clue the unsteadiness in walking and the inability to stand with the eyes closed. The cavity was largest in the cervical and upper 
dorsal regions, and to the corresponding part of the body the symptoms were, as we should expect, chiefly referred. There is no change which I have been able to associate with the presence of a zone of normal sensibility between the two zones of impairment. The distortion of the anterior horns and slight alteration in the cells, with perhaps the disappearance of some, are quite sufficient to account for the muscular atrophy, which was neither extensive nor extreme. The significance of the lateral sclerosis in reference to the exaggerated reflexes which were present is obvious. The change itself, in the absence of any other cause, may naturally be ascribed to the pressure exerted on these tracts by the great dilatation in the cervical region.

I may state in conclusion that from a consideration of this ease and others which I have seen or descriptions of which I have read I believe the condition now so generally known amongst neurologists as syringomyelia to depend upon different conditions. Clinically syringomyelia is broadly characterised by muscular wasting-often bilateral-and sensory symptoms, especially changes in sensibility to temperature and pain, while ordinary tactile sensibility may remain unchanged. These symptoms depend upon altered conditions in certain structures, and these structures may be injured in association, I believe, in different kinds of cases, to all of which the term "syringomyelia" is now applied. The two chief classes are, I think (and in this I only slightly alter Hoffmann's classification)-(1) those in which there is a congenital anomaly which may afterwards take on a process of overgrowth as distinguished from development; these are characterised clinically by the very gradual onset of symptoms, lasting, it may be, through many years; and (2) those in which there is actual central new growth, frequently with cavity formation, and, it may be, associated with new growth elsewhere-glioma, sarcoma or syphiloma, -and in which the course pursued is a much more rapidly fatal one. "That there are cases partaking of the characters of each, I have little doubt, but the clinical division into cases which are slow and cases which are rapid in progress will, I think, be generally acknowledged, and I believe it is correlated with the anatomical distinction which I have just stated.

Welbeck-street, $\mathrm{W}$.

\section{OBSERVATIONS ON THE PREVALENCE OF TYPHOID FEVER AMONGST BRITISH SOLDIERS IN GARRISON IN EGYPT.}

BY J. MACKIE, M.B., C.M.G.,

SURGEON TO H.M.'S CONSULATE-GENERAL, ALEXANDRIA.

OF the enemies with which the troops have had to contend since they landed in Egypt in 1882 the most dreaded by the common soldier, and perhaps the most fatal, is typhoid fever. This redoubtable enemy continues its ravages in regiment after regiment not only in the stirring times of war but in puaceful garrison duty, regardless of the lines of defence which have been set up against it. Brigade-Surgeon Gore, in his medico-statistical sketch of the British army in Egypt, states that from 1882 to 1889, in the whole Egyptian command, there were 2480 admissions to hospital for typhoid fever, with 704 deaths and 619 patients invalided. During the same period there were 9830 admissions from other continued fevers, with 9 deaths and 212 men invalided. As the Nile and Red Sea expeditions occurred in those years the statistics can hardly be held to apply to soldiers in garrison. The same authority, however, states that from 1883 to 1888,543 cases of typhoid fever were treated in the Cairo military hospital, the average strength of the garrison being in round numbers 3000 . In one of these vears, 1888, in addition to the cases classed as typhoid fever, 392 cases were admitted as simple continued fever, but there were no deaths. From February, 1883, to July 27th, 1888, there were treated in the military hospital at Alexandria 1683 cases of fever. The average number of the garrison is not stattd, but it was much inferior to that of Cairo. Of these cases of fever 820 were returned as simple continued fever, 239 as febriculæ, 393 as typhoid fever, 196 as ague and 35 as remittent fever. These statistics may also include invalids from some regiments which returned weary and wom from the Nile expedition. With regard to regiments which have suffered severely in peaceful garrison duty I would instance the Essex, which gamisoned Alexandria in 1890-91, and the Devonshire, which garrisoned Alexandria, occupying the same barracks in 1891 and 1892. The latter regiment arrived from England in the early summer of 1891 and remained comparatively free from fever returned as "typhoid" till the autumn of 1892. Up to Dec. 31st, 1891, there were returned 119 cases of fever-viz., 6 typhoid and 113 other continued and remittent fevers. During 1892, and chiefly during the few latter months there were returned 73 cases of typhoid fever with 23 deaths ; other continued and remittent fevers 155 , no deaths ; the strength of the regiment being about 800 .

The above figures will serve to give an idea of the prevalence of typhoid and other fevers amongst British troops in Egypt up to date, but the object of this paper is not to deal with statistics, which, however interesting and useful in a general way, are, without other data, often misleading and stop the way to more precise and, I would add, more scientific observation. Simple statistics alone do not recommend themselves to the unofficial mind; in the present instance they serve, however, to show the ravages committed amongst healthy troops by a disease which we are pleased to term "preventable." My intention is to point out some circumstances connected with the recurring epidemic outbreaks of typhoid fever amongst the soldiers in quiet garrison life, wellcared for and quartered in healthy localities, in the hope that it may lead to an investigation of the means of propagation and mears of prevention. My remarks must of necessity be confined to regiments quartered in Alexandria, as my means of information and local knowledge do not enable me at present to go further afield. First, then, I would remark that typhoid fever is endemic in Alexandria, cases occurring the whole year round with an increase generally in the autumn months. During the last summer and autumn, however, the general health of the population was excep tionally good, and very few cases of typhoid fever were observed in civil practice. Notwithstanding this a fatal epidemic declared itself amongst the soldiers of the Devonshire Regiment, 73 cases being trested chiefly in the few autumn months, with 23 deaths, and 155 cases of other continued fevers occurred during the year, many of the typhoid cases being of an exceedingly severe type and of a septic nature. The same was the history of the Essex Regiment and the Duke of Cornwall's Regiment, in which the disease assumed an epidemic and virulent form and propagated itself amongst the troops in garrison at a time when the civil population of the town, amounting to 240,000 , was comparatively free. All these regiments were quartered outside the town in what are considered healthy localities. The water supply and food were common to the military and civil population - in fact, in these respects the soldiers were probably better off and better looked after than three-fourths of the civil population, who are housed in insanitary dwellings in small unventilated lanes, drink filthy, unfiltered water and eat bad food. I do not refer to the native Egyptian only, but rather to the foreign or general European population, which may be considered to have the same liability to typhoid fever. The barracks in which the soldiers have been quartered may leare much to be desired compared with first-class barracks in England, but so does every "okella," as every densely populated block of buildings in Alexandria is called. The proprietors of these insanitary blocks will do nothing to improve them and there is no law to compel them, whilst the military authorities, guided by the Medical Staff and Royal Engineers, have spent immense sums on sanitary improvements, but the desired effect has not been obtained and epidemics of typhoid fever recur with fatal regularity. The barracks cannot be said to be overcrowded, as for several years there bas been only one regiment, not over 800 strong, in garrison, and during the hot autumn months the doors and windows are almost constantly open to admit the fresh breeze from the sea. One is forced to the conclusion that the generally accepted theory of the propagation of typhoid fever by water and drains alone will not explain such local epidemic outbreaks, and to seriously considering whether the disease, once it has obtained an entrance from without, is not propagated and transmitted from man to man amongst the soldiers themselves, gaining in virulence by transmission. That bad drains and bad water are predisposing and in many cases exciting causes is admitted, but our knowledge of bacteriology and the study of epidemic diseases teach us that we must not be too exclusive in our theories. Accepting the theory, then, as I do, of transmission from man to man, or in other words, contagion, as the cause of these virulent epidemics, what are the means to be adopted for prevention? Before touching on this let me draw attention to facts which 